\title{
PROBLEMÁTICA DE LOS PROCESOS DE VALORACIÓN URBANÍSTICA EN TÉRMINOS DE LA LEY 388 DE 1997.
}

\section{Jorge Eliécer Gaitán Torres ${ }^{1}$}

Dirección de proyectos de ordenamiento territorial

Recaman Koppel y Cia. Ltda. Bogotá, Colombia.

\author{
Jorge Eliécer Delgado Amaya ${ }^{2}$ \\ Subgerencia Tècnica \\ Recaman Koppel y Cia. Ltda. Bogotá, Colombia.
}

Remisión artículo: 07-06-2008

Remisión definitiva: 09-06-2008

Palabras Clave: Avalúos, Plusvalía, Expansión Urbana

Resumen: El propósito de este artículo es presentar ante la comunidad académica y la sociedad civil en general, un resumen de la historia valuatoria reciente en Colombia, algunas de sus vicisitudes, experiencias y estado del arte actual que, en desarrollo de algunos de los instrumentos de gestión de suelo previstos por la Ley 388 de 1997, presentan componentes o requieren de procesos de valoración. El artículo abarca únicamente lo referente a avalúos en suelos de expansión y cálculo del efecto plusvalía.

Si bien el artículo se desarrolla como un diagnóstico de los procesos de valoración para suelos de expansión urbana y para la captura del efecto plusvalía, se presentan dentro de las mismas posiciones personales de los autores sobre algunos elementos o componentes que, hoy por hoy, no se encuentran plenamente definidos en la estructura normativa o jurídica del país.

\section{Introducción}

Parte de la historia valuatoria de Colombia puede ser analizada a través de la actividad que hasta mediados de los 90 ejercían tanto las entidades públicas como los avaluadores particulares dedicados a esta actividad.

Para las entidades oficiales encargadas de elaborar avalúos de inmuebles, existen básicamente dos objetivos generales en el ejercicio de esta actividad: de una parte, la formación, actualización y conservación catastral, y de otra la realización de avalúos comerciales o avalúos especiales para las operaciones de adquisición y enajenación de inmuebles puntuales de interés para el Estado, o bien para propósitos específicos señalados en la ley.

En el primer caso, su función básica se refiere a la elaboración de las denominadas zonas homogéneas geoeconómicas y a su vez precisar el valor de las construcciones (mediante tablas y/o modelos de construcción) con el fin de establecer la base gravable del impuesto a la

\footnotetext{
${ }^{1}$ Jorge Eliecer Gaitán Torres, ingigaitan@yahoo.es, jgaitan@recamankoppel.com.co

2 Jorge Eliécer Delgado Amaya, jorged@recamankoppel.com.co, ingjda@yahoo.com
} 
propiedad raíz dentro del sistema tributario nacional. La forma de desarrollar esta actividad valuatoria se considera como una técnica masiva y se encuentra legislada por la Ley 14 de 1983 y sus decretos reglamentarios. En cuanto a la tarea de las entidades estatales para la elaboración de avalúos comerciales de bienes cuando su intención es vender o comprar propiedades en aplicación de objetivos específicos determinados por las leyes, por ejemplo, de reforma agraria y de reubicación de asentamientos en zonas de riesgo, entre otros fines, existen normas especiales que reglamentan la ejecución de este tipo de avalúos, bien sea con técnicas de tasación individual o masiva, así como guías para la elaboración de los mismos desarrolladas por el Instituto Geográfico Agustín Codazzi - IGAC, única entidad pública delegada para la determinación y aprobación de metodologías valuatorias, catastrales y comerciales para fines del Estado.

En cuanto a la actividad valuatoria privada, podría decirse que los primeros avaluadores particulares con que contó el país fueron aquellos propietarios de finca raíz o sus representantes o intermediarios, quienes debido al conocimiento del mercado inmobiliario y a las experiencias que habían tenido en la transacción de muchos de sus inmuebles, lograban identificar comportamientos en los valores; y mediante técnicas básicas de comparación ${ }^{3}$, conseguían determinar el valor de predios de terceras personas, de forma que el empirismo era total. Fueron pocos los avaluadores empíricos que intentaron desarrollar metodologías o técnicas que les permitieran analizar de forma coherente la información que manejaban y no se diseñaron manuales o promulgaron normas para regular esta actividad. Sin embargo, cuando existió un número significativo de personas dedicadas a esta actividad, en Bogotá primero ${ }^{4} \mathrm{y}$, un cuarto de siglo después, en otras ciudades principales del país, se crearon agremiaciones 0 colegios profesionales con miras a contribuir a la regulación del mercado y a establecer normas de ética y competencia entre sus asociados.

Años después, con la participación de estas asociaciones en eventos internacionales y su vinculación a organismos mundiales de profesionales inmobiliarios, se consideró necesaria una mayor preparación y adquisición de conocimientos sobre la materia. Por tanto los gremios y otras instituciones de investigación privadas, iniciaron la actividad de educación no formal en este campo, a través de una serie de eventos académicos con conferencistas internacionales que vinieron a nuestro país a contar sus experiencias ${ }^{5}$. Es así como en la década de los 80 recibimos una alta dosis de conocimiento de los brasileros, mientras en los 90 fuimos frecuentemente visitados por avaluadores mexicanos y hoy en día observamos con atención la técnica valuatoria de los españoles.

Posteriormente con la expedición de la Ley de Desarrollo Territorial, 388 de 1997, el tema de la valoración de la tierra se convirtió en una actividad transversal en el proceso de ordenamiento territorial que conllevó el desarrollo y adopción de una regulación específica en materia valuatoria $^{6}$. Sin embargo es de recordar que al gremio avaluador -en especial al privado, que para entonces ya tenía más de cincuenta años de tradición- le resultó difícil asumir en el corto

\footnotetext{
${ }^{3}$ Técnicas que no tenían un sustento científico o procedimiento claramente definido; su rigor estadístico era bastante bajo.

${ }^{4}$ La primera agremiación de este tipo constituida en 1945 en Colombia fue la sociedad anónima denominada Lonja de Propiedad Raíz, hoy corporación sin ánimo de lucro Lonja de Propiedad Raíz de Bogotá, cuyo esquema de realización de avalúos, denominados corporativos, siguieron las demás Lonjas y asociaciones avaluadoras que se constituyeron posteriormente, y particularmente, a partir de la posibilidad de participar en avalúos para el Estado a partir del DecretoLey 2150 de 1995.

${ }^{5}$ Experiencias que con el paso del tiempo se convirtieron en las reglas generales aceptadas en nuestro medio para el ejercicio valuatorio. Sin mayor adaptación a las circunstancias locales, se adoptaron normas de otros medios sociales y económicos y se utilizaron de manera incompleta las formulas presentadas por los expositores, entre otros factores.

${ }^{6}$ Se expidieron el Decreto 1420 de 1998 y la Resolución 762 del mismo año, reglamentarios de la Ley 388 de 1997, a efectos de determinar los métodos y procedimientos de valoración para los fines de dicha Ley.
} 
plazo y sin mayor preparación para el efecto la obligación de ejercer esta función pública por delegación, en una actividad desarrollada con un alto grado de empirismo y casi siempre para fines exclusivamente privados.

Debe tenerse en cuenta que en Colombia hasta la promulgación del Decreto-Ley 2150 en diciembre 5 de 1995 de supresión de trámites ante el Estado ${ }^{7}$, la realización de avalúos para las entidades estatales estaba asignada exclusivamente a los organismos públicos especializados: el IGAC y a los Catastros descentralizados existentes ${ }^{8}$. Mediante este DecretoLey, a efectos de agilizar trámites de expedientes de expropiación, y de adquisición o venta de bienes públicos, entre otros, se autorizó formalmente a las entidades estatales interesadas a solicitar los avalúos requeridos a entidades públicas o a avaluadores privados, según su libre escogencia. En caso de escoger la opción privada, el perito avaluador encargado debía ser designado por la Lonja o asociación profesional de avaluadores del lugar de ubicación del inmueble objeto de avalúo. De esta forma, las lonjas y asociaciones similares, pasaron a ejercer una función pública por delegación para la cual no estaban preparadas inicialmente ${ }^{9}$. Luego, la Ley 388 de 1997, retomó para los fines en ella establecidos el procedimiento determinado por el Decreto-Ley 2150 de 1995, haciendo mención específica al mismo ${ }^{10}$.

Es así como a través de los últimos años, al ampliar su campo de acción a los fines del Estado el uno y a las condiciones del mercado el otro, ambos segmentos del sector avaluador privado y público, han ido transformando tanto su forma de pensar como su técnica en la realización de los avalúos comerciales de que trata la Ley 388 de 1997. No obstante esta transición no ha sido rápida y en la mayoría de los casos el desconocimiento en la aplicación adecuada de los métodos legalmente aceptados, ha conducido a errores graves que a su vez llevan a una conclusión inadecuada de valor, siendo hoy por hoy una de las barreras que limitan la fluidez en el proceso de ordenamiento del territorio. En algunas ocasiones las malas prácticas valuatorias conducen a menoscabar el patrimonio o los intereses bien sean del Estado o de particulares, provocando que alguno de los partícipes se sienta lesionado sin justa causa.

7 "Por el cual se suprimen y reforman regulaciones, procedimientos o trámites innecesarios, existentes en la Administración Pública". Fue reformado parcialmente por la Ley 962 de julio 8 de 2005, pero quedó vigente, entre otros el artículo 27 del Decreto 2150 de 1995 relativo a avalúos.

\begin{abstract}
8 El único antecedente de participación de privados en el avalúo de bienes para fines Estatales se dio poco tiempo antes, con el Decreto 855 de abril 28 de 1994, por el cual se reglamentó parcialmente la Ley 80 de 1993 (Estatuto de Contratación Administrativa), en materia de contratación directa, así: "Artículo 15.- Para efectos de la venta o adquisición de inmuebles, las entidades estatales solicitarán un avalúo, que servirá como base de la negociación. Dicho avalúo será efectuado por el Instituto Geográfico Agustín Codazzi, previa solicitud de la entidad. Si pasados quince días hábiles contados a partir de la solicitud, ésta no fuere atendida o el Instituto manifestare su imposibilidad de hacerlo, la entidad contratará, con tal fin, una persona natural o jurídica experta en la materia."
\end{abstract}

9 "ART. 27.- Avalúo de bienes inmuebles. Los avalúos de bienes inmuebles que deban realizar las entidades públicas o que se realicen en actuaciones administrativas, podrán ser adelantados por el Instituto Geográfico Agustín Codazzi o por cualquier persona natural o jurídica de carácter privado, que se encuentre registrada y autorizada por la lonja de propiedad raíz del lugar donde esté ubicado el bien para adelantar dichos avalúos.

Parágrafo : Si la entidad pública escoge la opción privada, corresponderá a la Lonja determinar, en cada caso, la persona natural o jurídica que adelante el avalúo de bienes inmuebles."

${ }^{10}$ Fue sustituido en gran parte por la Ley 962 de julio 8 de 2005 "por la cual por la cual se dictan disposiciones sobre racionalización de trámites y procedimientos administrativos de los organismos y entidades del Estado y de los particulares que ejercen funciones públicas o prestan servicios públicos", pero quedó vigente, entre otros, el artículo 27 del Decreto 2150 de 1995 relativo a avalúos y por ende su mención específica en el artículo 61 de la Ley 388 de 1997. 
Para fortuna nuestra, Colombia ha venido avanzando en su desarrollo territorial a pasos agigantados que le han permitido posicionarse en los últimos años como uno de los líderes del tema en América Latina. Sin embargo, parte de ese ordenamiento territorial realizado a través de instrumentos como la plusvalía, los planes parciales y la renovación urbana, entre otros, tienen como punto fundamental de partida la valoración de los inmuebles involucrados en cada proceso, tarea que mal ejecutada retrasa o anula los proyectos planteados por el Estado.

Actualmente para efectos del ordenamiento, el territorio se ha dividido normativamente en zonas urbanas, rurales, de expansión urbana, renovación urbana y protección, donde las últimas tres denominaciones, corresponden a espacios físicos que no se enmarcan concretamente dentro de las metodologías valuatorias legalmente establecidas ${ }^{11}$, o necesitan de unas aplicaciones específicas, que permitan medir de manera correcta y acertada su valor comercial.

\section{Zonas de Expansión Urbana.}

Con la aparición de la Ley 388 de 1997 se introdujeron o precisaron algunos términos en materia urbanística que de una u otra forma afectarían el quehacer del gremio avaluador privado, el cual hasta ese entonces daba mayor relevancia a los aspectos físicos y económicos en los avalúos y dejaba un poco de lado las condiciones normativas, de situación jurídica y urbanística que regían para los predios objeto de estudio.

Uno de los nuevos términos que introdujo la Ley 388 de 1997 fue el de Zona de Expansión Urbana el cual corresponde a una porción del territorio que se habilitará para el uso urbano bajo ciertas condiciones; es decir se configuró legalmente una franja de transición que permite, de manera controlada en el tiempo y en condiciones de provisión de infraestructura, la incorporación del suelo rural al urbano, evitando el crecimiento inoportuno y desarticulado y la ocupación de usos urbanos en el área rural colindante con el área urbana.

De esta manera se creó para los avaluadores privados un escenario geoeconómico diferente que -la verdad sea dicha- no tuvo mayor trascendencia hasta mediados del año $2.003^{12}$, época en la cual el Gobierno Nacional con el apoyo del Lincoln Institute of Land Policy, intensificó la socialización y promoción a través de una serie de conferencias a lo largo del país $^{13}$, del uso de los instrumentos de gestión del suelo, financiación y desarrollo que fueron consagrados en la mencionada Ley de Desarrollo Territorial. ${ }^{14} \mathrm{~A}$ estas conferencias, se invitaron diferentes actores de la sociedad, entre ellos -claro está- los avaluadores privados, quienes empezaron a participar con algo de prevención sobre el tema, pero con curiosidad e interés por encontrar un papel más proactivo en esta nueva etapa del ordenamiento territorial.

El inicio no fue fácil, pues las primeras veces que los avaluadores privados asistieron a las conferencias de divulgación, flotaba en el ambiente el prejuicio del sector público y sus asesores respecto de este gremio, considerando que tan solo pensaba en el bienestar del particular y no asumía un alto compromiso con la comunidad; que sus dictámenes periciales tan solo favorecían la actividad de los constructores, atentando permanentemente contra la justa y equilibrada distribución de cargas y beneficios que demanda el desarrollo del territorio. Incluso en una ocasión llegó a exhibirse un avalúo comercial elaborado por uno de las más

\footnotetext{
${ }^{11}$ Decreto 1420 de 1998 y Resolución 762 de 1998.

${ }^{12}$ Cabe mencionar que a finales de ese año se efectuó la revisión del Plan de Ordenamiento territorial de la ciudad de Bogotá.

${ }^{13}$ Uno de estos eventos se realizó en mayo del 2.004 bajo el título "Región, Gestión del Suelo y Participación en Plusvalías. Los aportes de la ley 388 de 1997 a la gestión urbana y regional"

${ }^{14}$ En aquel entonces y en casi todos los escenarios donde se tocaba el tema de ordenamiento territorial, se repetía (como se sigue repitiendo hoy en día) que la Ley 388 de 1997, es una caja de herramientas sin explorar, que cuenta con un importante número de instrumentos de gestión del suelo y de financiación del desarrollo del territorio, que es hora de empezar a implementar.
} 
tradicionales Lonjas del país con el ánimo de evidenciar los grandes errores ${ }^{15}$ que se estaban cometiendo por parte de los peritos y descalificando de manera tajante el trabajo realizado.

No obstante todo lo anterior, y más allá de las fibras y sensibilidades que se tocaron en el proceso de enseñanza de los instrumentos de la Ley de Desarrollo Territorial, existía una dicotomía a la que debía enfrentarse el avaluador al abordar el estudio de las denominadas zonas de expansión urbana. Por un lado, el espíritu de la nueva legislación hace énfasis en la función social de la propiedad privada y el rechazo total al encarecimiento inapropiado del suelo que se encuentra justamente colindando con el área urbana de la ciudad, y por el otro, existía -y aún existe- un escenario socioeconómico que enmarca la actividad inmobiliaria en la zonas de expansión urbana, el cual refleja que la sociedad, en el complejo mundo de sus relaciones, acepta los valores de la tierra impuestos por el mercado; es decir, obedece al punto de equilibrio entre la oferta y demanda existentes, sin tomar en algunos casos su ajuste a la legalidad (normatividad).

Para el gremio avaluador privado, después del proceso de aprendizaje, quedó claro que una de las intenciones del Estado en el nuevo esquema de ordenamiento territorial, es capturar parte de las plusvalías o mayores valores que se generan por su actuación y evitar que los propietarios particulares se enriquezcan de manera injustificada por esta acción. El efecto de mayor valor o plusvalía se hace mucho más evidente justamente en las zonas de expansión urbana que de rurales pasan a ser urbanas, incrementando su valor de terreno en forma impactante y es allí donde podrían estar los mayores ingresos por plusvalía. Por este motivo se reiteraba entonces, al igual que hoy, que los avaluadores no deben tener en cuenta en la elaboración de los avalúos comerciales las expectativas futuras que se generan en las denominadas zonas de expansión urbana y que el valor comercial de estos terrenos tan solo debe fijarse basados en las condiciones de ubicación y fertilidad del suelo. Pese a entender la situación anterior, al comienzo cuando el avaluador se desplazaba a las zonas de expansión urbana y/o revisaba su archivo histórico, encontraba que los valores de transacción de la tierra superaban de manera considerable los valores que posiblemente podría obtener si se tuviera en cuenta tan solo la ubicación y productividad de los terrenos. Por ello la resistencia a adoptar esta forma de valoración y preferir continuar avaluando los terrenos de acuerdo con lo encontrado en el mercado.

Además de lo anterior, los planes de ordenamiento eran bastante imprecisos en el manejo de los suelos de expansión urbana; algunos como en el caso de Bogotá, señalaban los índices básicos de ocupación y construcción, así como el área de actividad, mientras otros iban más allá y establecían normas específicas para su desarrollo; es decir en ninguna parte estaba claro que estos suelos tendrían un uso rural y por ello debían valorarse bajo esa óptica. En esos momentos el avaluador no encontraba ningún argumento legal preciso que le permitiera afirmar que el suelo de expansión debía valorarse como suelo rural, y por el contrario encontraba un mercado lleno de transacciones que superaban este valor comercial. Es decir, si no existía una condición que cambiara el escenario, continuaría valorando el suelo de expansión urbana con un valor intermedio entre el valor del suelo rural y el valor del suelo urbano más próximo a éste.

Fue hasta diciembre del 2003, cuando la ciudad de Bogotá requirió elaborar los avalúos comerciales de referencia de un suelo de expansión urbana para la denominada Operación Estratégica Nuevo Usme, que se dio nuevamente la discusión sobre la forma de valorar este tipo de suelo. La Administración Distrital concluyó que la mejor alternativa para superar las diferencias de criterio era establecer a través de la legislación una base jurídica que le permitiera a los avaluadores valorar el suelo de expansión urbana como suelo rural, y fue así como en el Decreto 469 de $2003^{16}$ se incluyó un artículo que dejó en claro cual es el uso de los

\footnotetext{
${ }^{15}$ Se tildó como error la normativa urbanística aplicada y el método valuatorio empleado.

${ }^{16}$ Decreto Distrital por el cual se revisó el Plan de Ordenamiento Territorial de Bogotá, D.C., adoptado mediante el Decreto 619 de 2.000. Estos decretos fueron compilados en el Decreto Distrital 190 de 2.004.
} 
terrenos de expansión ${ }^{17}$ y la forma de valorarlos ${ }^{18}$, herramienta suficiente para que los avaluadores Bogotá ejecutaran su labor sin restricción técnica alguna.

Lo anterior fue un gran avance para la ciudad de Bogotá, pero aún el resto del país continuaba con el problema y era necesario solucionarlo; por ello de manera acertada el Ministerio de Ambiente Vivienda y Desarrollo Territorial tomó cartas en el asunto y a través del Decreto 2181 de 2006 estableció a nivel nacional los usos de los suelos de expansión urbana brindando nuevamente a los avaluadores una base legal firme para su labor de valoración.

\section{Estado actual y proceso de implementación del efecto plusvalía.}

Para poder desarrollar un análisis de la captura que en términos de plusvalías ha implementado y logrado recaudar el Estado colombiano, debe presentarse de manera simple el estado actual del arte y sus antecedentes. Es así que la expedición de la Ley 388 de 1997, marca el inicio desde el punto de vista jurídico, de los procesos del cálculo del efecto plusvalía en nuestra estructura de ordenamiento territorial. Aunque desde la Ley 9a de 1989 conocida como Ley de Reforma Urbana, ya se había incluido esta figura bajo la denominación de Contribución al Desarrollo Municipal ${ }^{19}$, ésta nunca logró ser implementada en la práctica.

En este sentido, hasta antes de la promulgación de la Constitución de 1991, al Estado parecía importarle poco capturar el efecto que causaban sus actuaciones en el valor de los terrenos urbanos o rurales y mucho menos observar o controlar de forma alguna los altos grados de especulación que se originaban, bien fuera en los terrenos colindantes con el área urbana o en aquellos terrenos desarrollados de forma ilegal ${ }^{20}$. Es hasta la aparición del artículo 82 de la Constitución Nacional, que a su tenor establece que "Las entidades públicas participarán en la plusvalía que genere su acción urbanística y regularán la utilización del suelo y del espacio aéreo urbano en defensa del interés común", cuando el Estado finalmente se obliga a medir su aporte a la conformación del valor de los terrenos y recuperar parte de este aporte para ser reinvertido en la sociedad.

Solo hasta el inicio del presente siglo, por parte de la academia y de algunas agremiaciones, se inician procesos de capacitación y divulgación del tema, el cual en un comienzo -y aún todavía- se ha fundamentado en el desarrollo teórico de la plusvalía, dejando de lado el proceso de capacitación y formación directa de los funcionarios de entes administrativos municipales, la rama judicial (concretamente Notariado), el gremio de avaluadores, los constructores, y el público en general (que incluye la academia, entre otros). Solo hasta el año 2004 y por convocatoria de Ministerio de Ambiente, Vivienda y Desarrollo Territorial, el Departamento Administrativo de Planeación Distrital, el Lincoln Institute of Land Policy, el

\footnotetext{
${ }^{17}$ Una parte del Artículo 42 del Decreto 190 de 2004 establece lo siguiente: "En el caso de suelos clasificados como de expansión urbana, de conformidad con el parágrafo 1 del artículo 89 del Decreto 619 de 2000 tendrán usos forestales y agropecuarios hasta tanto no se incorporen al perímetro urbano mediante Planes Parciales, por tanto se valorarán teniendo en cuenta exclusivamente criterios de localización y productividad rural". (Subrayado fuera de texto).

${ }^{18}$ El Decreto 190 de 2004 en su artículo 53, menciona "Artículo 53. Reglas para la elaboración de avalúos (artículo 53 del Decreto 469 de 2003).

Para dar cumplimiento a lo dispuesto en el artículo 61 de la ley 388 de 1997 y en el Articulo. 21 del Decreto 1420 de 1998, las entidades distritales que realicen o soliciten la realización de avalúos para cualquier finalidad, verificarán que se tenga en cuenta la reglamentación urbanística vigente en el momento de la realización del avalúo, y que en ningún caso se incorporen meras expectativas en los precios de los inmuebles avaluados.
}

${ }^{19}$ Ver Artículos 107 a 111 de la Ley 9a de 1989 "Por la cual se dictan normas sobre planes de desarrollo municipal, compraventa y expropiación de bienes y se dictan otras disposiciones".

${ }_{20}$ Entiéndase desarrollos sin el lleno de los requisitos, en términos generales. 
CIDER, la Universidad de Los Andes y Fedevivienda, se produce una de las primeras conferencias que abandera el proceso. A partir de ese año y durante los dos siguientes se realizaron varios eventos ${ }^{21}$ que, como se anotó antes, presentaron un alto contenido teórico, sin entrar a precisar experiencias, limitaciones y dificultades del cálculo y la aplicación de la plusvalía debido a la poca experiencia acumulada en el país sobre esta materia.

Por otra parte el número de municipios que ha recibo capacitación sobre el particular, no supera la cantidad de 20, cifra que comparada contra los cerca de 1.100 municipios existentes en Colombia, es bastante baja y muy poco representativa; sin embargo son pocos los municipios que cuentan con elementos normativos y urbanísticos que pueden generar Participación en la Plusvalía. A través de la experiencia de los autores y su contacto con las administraciones municipales, se observa un grado de incertidumbre y un interés bajo o nulo en la implementación del cálculo, liquidación y cobro de la Participación en la Plusvalía. Sin embargo, se debe resaltar que el artículo 82 de la Constitución Política de Colombia señala como un imperativo el hecho de que las entidades territoriales participen en la plusvalía, excluyendo por tanto la posibilidad de que la participación sea facultativa ${ }^{22}$.

A la fecha, la implementación de la Participación en la Plusvalía, solo se ha cumplido en algunas ciudades del país, sin tener el efecto que el Estado esperaba, tanto en el número de municipios que hacen uso de este instrumento, como en la captura de ingresos por este concepto. De otra parte, los cálculos del efecto plusvalía solo se han desarrollado para algunas clases de suelo; es decir, no se ha generado este cálculo en todos los tipos de suelo. La tabla No. 1 siguiente, muestra los municipios sobre los cuales se han desarrollado procesos de implementación y cálculo del efecto plusvalía, así como sobre los tipos de suelo en los cuales éstos se han aplicado.

TABLA 1

MUNICIPIOS CON CÁLCULO DE PLUSVALIA SEGÚN CLASES DE SUELO

\begin{tabular}{|c|c|c|c|c|}
\hline MUNICIPIO & $\begin{array}{c}\text { ÁREA } \\
\text { URBANA }\end{array}$ & $\begin{array}{c}\text { ÁREA DE } \\
\text { EXPANSIÓN }\end{array}$ & $\begin{array}{c}\text { ÁREA } \\
\text { RURAL }\end{array}$ & $\begin{array}{c}\text { PLANES } \\
\text { PARCIALES }\end{array}$ \\
\hline BOGOTÁ & $\mathrm{SI}$ & $\mathrm{SI}$ & $\mathrm{NO}$ & SI \\
\hline MONTERÍA & $\mathrm{SI}$ & $\mathrm{NO}$ & $\mathrm{NO}$ & $\mathrm{NO}$ \\
\hline FUSAGASUGA & $\mathrm{NO}$ & $\mathrm{SI}$ & $\mathrm{NO}$ & $\mathrm{NO}$ \\
\hline PEREIRA & $\mathrm{NO}$ & $\mathrm{NO}$ & $\mathrm{NO}$ & $\mathrm{SI}$ \\
\hline FACATATIVA & $\mathrm{NO}$ & $\mathrm{SI}$ & $\mathrm{NO}$ & $\mathrm{SI}$ \\
\hline CALI & $\mathrm{SI}$ & $\mathrm{NO}$ & $\mathrm{NO}$ & $\mathrm{NO}$ \\
\hline
\end{tabular}

Fuente: Elaboración propia, datos a diciembre de 2007.

Como se puede observar, la implementación y el cálculo de la plusvalía en Colombia se reduce a muy pocos municipios y se aplica solo para algunas clases de suelo, siendo Bogotá la ciudad que ha desarrollado en mayor número y cobertura el cálculo del efecto plusvalía. Aunque un número mayor de municipios ha desarrollado y adoptado el acto normativo (Acuerdo del Concejo municipal) por el cual se establecen las normas para la aplicación de la participación en plusvalías, éstos no superan la veintena y muchos de los acuerdos ya existentes, en algunos apartes superan las condiciones que la Ley 388 de 1997 definió en este sentido.

Si bien es cierto que el número de municipios en los que se ha implementado la Participación en Plusvalía es bajo, también es cierto, que un buen número de municipios -ya sea por falta de compromiso político, desconocimiento o simplemente inexistencia de interés en su aplicaciónhan permitido que esos mayores valores que toma el suelo a través de su propia acción

\footnotetext{
${ }^{21}$ Convocados básicamente por el Lincoln Institute of Land Policy, el CIDER, la Universidad de Los Andes.

${ }^{22}$ Tomado del Concepto No. 0013 de fecha 05 de mayo de 2000, expedido por el Ministerio de Hacienda y Crédito Público.
} 
urbanística sigan siendo captados íntegramente por los propietarios del suelo, sin que se les exija la participación parcial al Estado a la que estarían obligados. Es decir, se puede concluir que por efecto de la no implementación del instrumento, se presenta una pérdida de captura de plusvalías que bien podría constituirse en un detrimento patrimonial del Estado.

Otra de las situaciones observadas - posiblemente por no contar con unas reglas o técnicas únicas de cálculo y/o procedimientos únicos para el establecimiento del efecto plusvalía, o por existir en los elementos normativos que regulan el mismo, situaciones de ambigüedad o vacío jurídico- han generado, ya sea por parte de las oficinas de planeación municipal o por, los gremios o entes encargados de los cálculos, interpretaciones y/o ajustes que, en términos de la Ley, desvirtúan el principio rector de la plusvalía, desbordan su aplicación o simplemente se desarrollan bajo la interpretación de la persona o equipo de turno. Ante ello, el Estado ha tenido que producir doctrina normativa que regule su aplicación y de la cual se debe decir, que, aún siendo un avance, no es el punto final al que debe orientarse la implementación y cálculo del efecto plusvalía.

En concepto de los autores, la Participación en la Plusvalía, debe ser analizada en función de la relación Beneficio/Costo que ésta genere sobre la municipalidad. Bajo esta óptica, no todos los municipios deberán desarrollar estos procesos, ya que para algunos, -probablemente los más pequeños y/o con poca dinámica de crecimiento o cambio,- pueden resultar más altos los costos de la implementación y cálculo que los posiblespotenciales ingresos que sea posiblefactible o se espere percibir, en función de los hechos generadores de plusvalía que resulten de los cambios en el planeamiento y la normatividad urbanística previstos en la vigencia de sus planes de ordenamiento. Lo anterior hace necesario iniciar un proceso de jerarquización de los municipios según su real potencial de desarrollo y evidenciar que la Participación en la Plusvalía no es simplemente un recurso fácil al que puede apelarse para aumentar sus ingresos, como parecen pensar algunos luego de las argumentaciones de las ventajas fiscales del uso de este instrumento,; en estos casos deberán desarrollardesarrollarse ejercicios de precalculo, precálculo de plusvalía que permitan diagnosticar la situación del municipio, frente a la plusvalía y si debe, de acuerdosolo cuando se justifique conforme a su evaluación técnica, implementar los procesos de cálculo y liquidación de la misma.

\section{El galimatías de la plusvalía en los suelos rurales}

¿Deberán los predios localizados en las zonas rurales realizar la contribución de Participación en Plusvalía? Ante una inquietud como la referida -que no debería ser una pregunta, sino una afirmación- se debe anotar que buena parte de los gremios, municipios, académicos y propietarios, responden negativamente, lo cual se explica en la interpretación incompleta que al parecer hacen de algunos artículos de la Ley 388 de 1997 relativos a la noción y acciones generadoras de plusvalía.

En primer lugar, cuando el legislador señala en el artículo 73 de la Ley 388 de 1997: "NOCIÓN. De conformidad con lo dispuesto por el artículo 82 de la Constitución Política, las acciones urbanísticas que regulan la utilización del suelo y del espacio aéreo urbano incrementando su aprovechamiento, ..." (subrayado fuera del texto), se realiza la lectura por una parte de los gremios, municipios y otros, como si únicamente se estuviera haciendo referencia a las acciones urbanísticas que tienen que ver con el suelo urbano. Pero tal y como lo señala la Constitución Política en su artículo 82, “... Las entidades públicas participarán en la plusvalía que genere su acción urbanística y regularán la utilización del suelo y del espacio aéreo urbano en defensa del interés común", (subrayado fuera de texto), el principio de la plusvalía no está dirigido a una clase de suelo en específico y solo enuncia que la acción urbanística del Estado es generadora de plusvalía. 
Un segundo aspecto de la redacción de la Ley que ha causado polémica en relación a si los suelos rurales son o no generadores de plusvalía, se refiere al contenido del artículo 74 de la Ley 388 de 1997, por el hecho que éste no hace alusión expresa al suelo rural en los hechos generadores por establecimiento o modificación del régimen o la zonificación de usos del suelo ni a la autorización de un mayor aprovechamiento del suelo en edificación, bien sea elevando el índice de ocupación o el índice de construcción, o ambos a la vez, interpretación que no tiene sustento por cuanto, estos hechos generadores sí pueden configurarse en las zonas rurales.

En concepto de los autores, los suelos rurales deben ser objeto de participaciónParticipación en plusvalíala Plusvalía, siempre y cuando se genere una acción urbanística que signifique para el predio modificaciones en su régimen de usos y un mayor aprovechamiento del suelo.

\section{La Participación en Plusvalía controla el valor del suelo?}

Se ha dicho en varios medios y por diferentes voceros que la Participación en la Plusvalía, permite controlar el valor en el mercado del suelo; en este sentido se presenta a continuación una serie de elementos teóricos y de experticia, que permiten llegar a una aseveración en este sentido.

En forma general la dinámica propia del mercado del suelo al interior de un sistema económico de tipo capitalista como el colombiano, establece en principio que la formación de los valores de la tierra no es otra cosa que la capitalización de las rentas futuras o la acumulación de plusvalías futuras, basadas en las potencialidades de explotación que puedan llegar a tener los terrenos. Y es a partir de este punto que debemos analizar la manera en que un instrumento de financiación del desarrollo como la Participación en la Plusvalía logra controlar el valor en el mercado del suelo. Es necesario entonces estudiar más a fondo la formación del precio del suelo desde el área rural para posteriormente pasar al área urbana y observar las alteraciones y el grado de especulación de las transacciones. Si se entiende el procedimiento "natural" de la formación del suelo y el grado de influencia de las acciones o actuaciones urbanísticas del Estado, podremos entender la manera en que la Participación en la Plusvalía puede llegar a controlar el mercado del suelo al interior de las ciudades colombianas.

Como se puede extraer de lo anterior, bien sea en los terrenos rurales o en los urbanos, el valor comercial del suelo depende directamente de las posibilidades reales de explotación; no obstante es de tener en cuenta que gran parte de estas posibilidades o potencialidades radican en las normas urbanísticas establecidas. Es así como terrenos urbanos con ubicación y capacidad portante similar, pueden tener un valor comercial diferente debido a la norma urbanística que los cobija; un ejemplo claro son los predios ubicados en la zona del Chicó ${ }^{23}$ en Bogotá, algunos de ellos con autorización para construir 5 pisos de altura y otros con permiso para construir hasta 7 pisos, los cuales presentan comercialmente valores de $\$ 2,300.000$ y $\$$ 2’900.000 respectivamente, pese a tener condiciones físicas y socieconómicas muy similares.

Desafortunadamente, y debido en parte a la permisividad del Estado, se desarrollaron en las zonas rurales colindantes a la ciudad usos que la norma urbanística no permitía, como las parcelaciones o algunos condominios de la zona conocida como Guaymaral al norte de la ciudad de Bogotá, circunstancia que originó un valor comercial del suelo bastante lejano de la potencialidad legal establecida por la normas urbanísticas de la zona. Este valor comercial se formó en la ilegalidad y por lo tanto no debe ser tenido en cuenta dentro de un mercado formal, transparente y equitativo; es decir estos valores especulativos no pueden formar parte de un estudio que tenga como fin determinar el valor comercial de un predio ubicado en zonas aledañas a los cascos urbanos de las ciudades.

\footnotetext{
${ }^{23}$ Sector norte de la Ciudadciudad de Bogotá, de estrato socioeconómico alto.
} 
Si bien es claro cómo se forma el precio del suelo y que el Estado tiene la obligación de recuperar parte del precio que gracias a su acción se ha formado, no es del todo claro cómo la aparición de este instrumento denominado "Participación en la Plusvalía" contribuye a controlar el mercado del suelo. Para ello es necesario observar diferentes escenarios, los cuales se presentan en la Tabla No. 2 que sigue a continuación.

TABLA 2 COMPARACIÓN DEL PROCESO VALUATORIO ANTES Y DESPUÉS DE LA LEY 388 DE 1997

\begin{tabular}{|c|c|c|}
\hline & $\begin{array}{c}\text { Antes de la } \\
\text { Ley } 388 \text { de } 1997\end{array}$ & $\begin{array}{l}\text { Con la Aparición } \\
\text { de La Plusvalía }\end{array}$ \\
\hline $\begin{array}{l}\text { Suelo Urbano } \\
\text { Consolidado }\end{array}$ & $\begin{array}{l}\text { El valor comercial de los terrenos estaba } \\
\text { directamente relacionado con las } \\
\text { oportunidades inmobiliarias del momento } \\
\text { y la potencialidad legal que la norma } \\
\text { urbanística establecía. }\end{array}$ & $\begin{array}{l}\text { El valor comercial del suelo conserva el mismo } \\
\text { principio de formación del valor, es decir la plusvalía } \\
\text { no interviene ni controla el mercado de estos suelos; } \\
\text { simplemente se limita a recaudar el incremento de } \\
\text { valor resultante de la acción del Estado. En términos } \\
\text { de un mercado inmobiliario activo, la aparición de la } \\
\text { "Participación en Plusvalía" no altera el mercado de } \\
\text { este tipo de suelo, ni como erróneamente se cree } \\
\text { aumenta de manera alguna el valor del producto } \\
\text { final. }\end{array}$ \\
\hline Suelo de Expansión & $\begin{array}{l}\text { Este tipo de suelo no existía a nivel } \\
\text { normativo, sin embargo claramente se } \\
\text { entiende que es suelo colindante con el } \\
\text { área urbana. El comportamiento de los } \\
\text { valores comerciales era bastante } \\
\text { especulativo y el propietario de la tierra } \\
\text { se apropiaba de todas aquellas } \\
\text { expectativas futuras que se generaban } \\
\text { por el simple hecho de estar estos } \\
\text { terrenos colindantes a las áreas } \\
\text { urbanas. } \\
\text { En otras ocasiones estos terrenos } \\
\text { usualmente se parcelaban o subdividían } \\
\text { por debajo del área mínima establecida } \\
\text { en las respectivas normas urbanísticas } \\
\text { de cada municipio y hacia aplicación de } \\
\text { procesos de división como si fueran } \\
\text { terrenos urbanos. } \\
\text { Estos fenómenos elevaban de manera } \\
\text { exponencial el valor de los terrenos, y en } \\
\text { consecuencia al pasar a ser urbanos, } \\
\text { tomaban un valor tan alto que } \\
\text { impactaban directamente en el valor } \\
\text { comercial del producto final. } \\
\text { Esta característica poco deseable } \\
\text { disminuía de manera ostensible las } \\
\text { posibilidades de construcción de } \\
\text { vivienda de interés social, pues diferente } \\
\text { a la vivienda de estrato alto que puede } \\
\text { elevar los valores comerciales del } \\
\text { producto final, la vivienda de interés } \\
\text { social se encuentra enmarcada dentro } \\
\text { de unos márgenes de negociación y } \\
\text { soportado sobre un programa de } \\
\text { subsidios del Estado, y por lo tanto se } \\
\text { dificultaba bastante conseguir terrenos } \\
\text { cuyo valor comercial permitieran el } \\
\text { desarrollo de vivienda de Interés social. }\end{array}$ & $\begin{array}{l}\text { Al definir jurídicamente que el suelo de expansión } \\
\text { está constituido por la porción del territorio municipal } \\
\text { destinada a la expansión urbana, que se habilitará } \\
\text { para el uso urbano durante la vigencia del plan de } \\
\text { ordenamiento, y que a partir de ese momento el } \\
\text { Estado participaría de los mayores valores que su } \\
\text { actuación (en este caso dejar de ser suelo rural) } \\
\text { generara en el valor del suelo, quedó en claro que el } \\
\text { mercado de este tipo de inmuebles tenía un actor } \\
\text { más a tener en cuenta y que los valores comerciales } \\
\text { se encontrarían sujetos no solo a las fuerzas } \\
\text { especulativas del mercado sino a las realidades } \\
\text { normativas que desde ese momento y con mayor } \\
\text { interés haría cumplir el Estado. } \\
\text { Posteriormente se determinó que los suelos de } \\
\text { expansión "Mientras no se aprueben los respectivos } \\
\text { planes parciales, en las zonas de expansión urbana } \\
\text { solo se permitirá el desarrollo de usos agrícolas y } \\
\text { forestales. En ningún caso se permitirá el desarrollo } \\
\text { de parcelaciones rurales para vivienda campestre"24, } \\
\text { por lo tanto se deja en claro la potencialidad actual } \\
\text { de este tipo de suelos y se liga el valor comercial de } \\
\text { estos terrenos a la actividad propiamente rural, es } \\
\text { decir se elimina todo aquel grado de especulación } \\
\text { que tenían los precios de los terrenos por las } \\
\text { expectativa que estos tenía de ser urbanos. }\end{array}$ \\
\hline
\end{tabular}

\footnotetext{
${ }^{24}$ Apartes del Artículo 29 del Decreto 2181 DE 2006
} 


\begin{tabular}{|c|c|c|}
\hline $\begin{array}{l}\text { Ocupación } \\
\text { Ilegal }\end{array}$ & $\begin{array}{l}\text { Los urbanizadores piratas no sólo han } \\
\text { recuperado todos los incrementos del } \\
\text { precio derivado del desarrollo urbano, } \\
\text { sino que además han tomado bajo } \\
\text { control el proceso. La urbanización ilegal } \\
\text { resultante es costosa para los ocupantes } \\
\text { individuales de dichos asentamientos y } \\
\text { para la sociedad como un todo, ya que } \\
\text { eleva el costo de los futuros programas } \\
\text { de mejoras entre tres y cinco veces, en } \\
\text { comparación con el costo de urbanizar } \\
\text { suelo no ocupado }\end{array}$ & $\begin{array}{l}\text { La proliferación de loteos ilegales tiene básicamente } \\
\text { dos orígenes: el primero la falta de control policivo } \\
\text { del Estado y el segundo la capacidad de compra de } \\
\text { los estratos más bajos que encuentran en este tipo } \\
\text { de desarrollo ilegal un valor del suelo asequible a su } \\
\text { posibilidades económicas inmediatas. Al respecto } \\
\text { vale la pena tomar el siguiente texto: } \\
\text { "Uno de los aspectos más importantes del estudio } \\
\text { de políticas de suelo en América Latina es la falta de } \\
\text { tierra urbanizada al alcance de los habitantes de } \\
\text { bajos recursos. Esta carencia, y la consiguiente } \\
\text { ocupación ilegal de terrenos carentes de } \\
\text { infraestructuras, son características de las ciudades } \\
\text { latinoamericanas, especialmente en las periferias } \\
\text { urbanas y en áreas no aptas para el mercado } \\
\text { inmobiliario (o excluidas del mismo) debido a sus } \\
\text { condiciones topográficas o ambientales."26 } \\
\text { Si a través de los instrumentos de desarrollo se } \\
\text { genera una oferta de terrenos de precio asequible a } \\
\text { los estratos bajos y a su vez se desestimula al } \\
\text { urbanizador ilegal, bajando la presión por este tipo } \\
\text { de producto (lotes ilegales) el valor comercial de los } \\
\text { terrenos definitivamente se podrá controlar. }\end{array}$ \\
\hline
\end{tabular}

Fuente:

Elaboración propia.

Como se puede observar, los anteriores escenarios permiten evidenciar que realmente son las normas urbanísticas las que de una $u$ otra forma regulan el valor comercial de los terrenos y por lo tanto no es del todo claro cómo la Participación en la Plusvalía controla el mercado del suelo.

Con relación a las afirmaciones que se hacen en la Tabla No. 2 anterior respecto al comportamiento del valor del suelo urbano consolidado con la aparición de la Participación en la Plusvalía, podemos realizar un análisis básico que nos permite visualizar (Ver Tabla 3) este fenómeno a partir del siguiente ejemplo ${ }^{27}: 28$ (Ver Tabla 3):

TABLA 3. ZONA URBANA CONSOLIDADA

\begin{tabular}{|l|l|}
\hline \multicolumn{1}{|c|}{ NORMA ANTERIOR } & \multicolumn{1}{c|}{ NORMA ACTUAL } \\
\hline ALTURA & ALTURA \\
PERMITIDA: 6 PISOS & PERMITIDA: 8 PISOS \\
USO: RESIDENCIAL UNICAMENTE. & USO: RESIDENCIAL UNICAMENTE. \\
AREA TOTAL VENDIBLE: $1.900 \mathrm{M}^{2}$ & AREA TOTAL VENDIBLE: $2.500 \mathrm{M}^{2}$ \\
Valor de venta Producto final: $\$ 2^{\prime} 200.000 / \mathrm{M}^{2}$ & Valor de venta Producto final: $\$ 2^{\prime} 200.000 / \mathrm{M}^{2}$ \\
AREA LOTE: $800 \mathrm{M}^{2}$ & AREA LOTE: 800 $\mathrm{M}^{2}$ \\
VALOR UNIT. LOTE: $\$ 1^{\prime} 000.000 / \mathrm{M}^{2}$ & VALOR UNIT. LOTE: $\$ 1^{\prime} 200.000 / \mathrm{M}^{2}$ \\
VALOR TOTAL $\$ 800^{\prime} 000.00$ & VALOR TOTAL $\$ 960^{\prime} 000.00$ \\
\hline \multicolumn{2}{|c|}{ PLUSVALÍA TOTAL $=\$ 960^{\prime} 000.000-\$ 800^{\prime} 000.000=\$ 160^{\prime} 000.000$} \\
\hline
\end{tabular}

Fuente: Elaboración propia.

\footnotetext{
${ }^{25}$ Tomado del documento Exposición de motivos, presentado al Concejo de Bogotá, para la aprobación del Acuerdo de Plusvalía respectivo.

${ }^{26}$ Land Lines: July 1999, Volume 11, Number 4, ), Smolka, Martim O. y Iracheta Cenecorta, Alfonso

27 Los valores unitarios que se utilizan son parte del ejemplo y no están referidos a espacios geográficos puntuales.

${ }^{28}$ Los valores unitarios que se utilizan son parte del ejemplo y no están referidos a espacios geográficos puntuales.
} 
Ahora bien, si por ejemplo, un constructor sale al mercado a comprar un terreno para desarrollar un proyecto residencial en un lote de $800 \mathrm{M} 2$ con una altura permitida de 8 pisos, encontrará el mercado dos alternativas (ver tabaTabla 4);): la primera, enfocada enserían los lotes del área y localización requerida que antes de la nueva norma urbanística tenían y con la norma actual tienen autorización para construir 8 pisos de altura y cuyo valor es de $\$ 1^{\prime} 200.000$ $\mathrm{M}^{2}$ (situación 1); la segunda alternativa para comprar el lote que busca, la encontrará en aquellos predios que gracias alde las características deseadas, que antes del cambio normativo hoy pueden construir 8 pisos de alturapodían edificar una altura (posibilidad que antes no tenían) de 6 pisos y valían $\$ 1$ '000.000 M ${ }^{2}$ y que lógicamente hoy también tienenhoy, luego de que las normas vigentes le aumentaran el potencial de edificación a 8 pisos de altura, pasaron a tener un valor por metro cuadrado de $\$ 1^{\prime} 200.000 / \mathrm{M}^{2}$ (situación 2)), es decir el mismo que sus símiles.

TABLA 4. MERCADO ACTUAL

\begin{tabular}{|c|c|}
\hline Situación 1. & Situación 2. \\
\hline $\begin{array}{l}\text { ALTURA } \\
\text { PERMITIDA: } 8 \text { PISOS } \\
\text { USO: RESIDENCIAL UNICAMENTE. } \\
\text { AREA TOTAL VENDIBLE: } 2.500 \mathrm{M} 2 \\
\text { Valor de venta Producto final: } \$ 2^{\prime} 200.000 / \mathrm{M} 2 \\
\text { AREA LOTE: } 800 \mathrm{M} 2 \\
\text { VALOR UNIT. LOTE: } \$ 1^{\prime} 200.000 / \mathrm{M} 2 \\
\text { VALOR TOTAL } \$ 960^{\prime} 000.00\end{array}$ & $\begin{array}{l}\text { ALTURA } \\
\text { PERMITIDA: } 8 \text { PISOS } \\
\text { USO: RESIDENCIAL UNICAMENTE. } \\
\text { AREA TOTAL VENDIBLE: } 2.500 \mathrm{M}^{2} \\
\text { Valor de venta Producto final: } \$ 2^{\prime} 200.000 / \mathrm{M}^{2} \\
\text { AREA LOTE: } 800 \mathrm{M}^{2} \\
\text { VALOR UNIT. LOTE: }\left(\$ 1^{\prime} 000.000+\$ 200.000=\right. \\
\$ 1^{\prime} 200.000 / \mathrm{M}^{2} \\
\text { VALOR TOTAL } \$ 960^{\prime} 000.00\end{array}$ \\
\hline
\end{tabular}

Fuente: Elaboración propia.

Como se puede observar, para el constructor es indiferente adquirir un predio que haya sido objeto del efecto plusvalía o uno que no; simplemente él, de acuerdo a la potencialidad del lote y a los valores de venta del mercado estará dispuesto a pagar por uno o por otro la suma de $\$ 1^{\prime} 200.000 / \mathrm{M}^{2}$, y el valor de la venta o producto final no debe ser alterado.

Adicionalmente se debe recordar que existe una anotación en el folio de matrícula inmobiliaria que advierte cuándo un lote ha sido objeto de participación en plusvalía; por lo tanto el comprador (por ejemplo un constructor) se encuentra advertido de esta situación y dentro del proceso de negociación quedará en claro que él está dispuesto a pagar por el lote a razón de $\$ 1^{\prime} 200.000 \mathrm{M}^{2}$ y que obviamente la participación en plusvalía deberá ser cubierta por el actual propietario.

Por todo lo anterior se puede concluir que en términos de un mercado inmobiliario activo, la aparición de la "Participación en Plusvalía" no altera el mercado de este tipo de suelo (suelo urbano consolidado), ni como erróneamente se cree, aumenta de manera alguna el valor del producto final.

Ahora bien, para los escenarios de Suelo de Expansión y Ocupación llegal tampoco se puede concluir que la aparición del instrumento de la Participación en la Plusvalía intervenga "directamente" o sea el único instrumento que controla el mercado del suelo; no obstante hay que entender el instrumento en su totalidad y debemos recordar que una de las destinaciones que se prevén para los recursos captados mediante este instrumento, es la compra de terrenos para proyectos de interés social, macroproyectos, programas de renovación urbana, etc., destinaciones que permiten que el Estado se pueda volver un actor más del mercado inmobiliario y entre a competir con urbanizadores piratas al poder ofrecer terrenos 
urbanísticamente adecuados, dotados de la infraestructura necesaria y con ofertas comerciales atractivas al alcance del grupo de la población de menores recursos.

Por otra parte si el Estado se convierte en un oferente de terrenos debidamente urbanizados y los ofrece a valores que permitan que un constructor pueda desarrollar vivienda de Interésinterés social al alcance de los potenciales demandantes, afecta en gran medida las ofertas del mercado ilegal y controla el valor comercial de los lotes urbanos aún sin desarrollar que se encontraban especulando en el mercado.

Una claro ejemplo de esta situación se puede ver en la ciudad de Bogotá con los programas de urbanización de Metrovivienda. Desde que se inició este programa los lotes de desarrollo de estrato 1 y 2 han venido reduciendo en forma vertiginosa su valor comercial y en su mayoría no son atractivos para un constructor que en vez de desembolsar una gran cantidad de dinero para comprar un lote en bruto, urbanizarlo y posteriormente publicitar su producto, prefiere comprar un lote urbanizado en Metrovivienda desembolsando un menor monto (pues puede comprar tan solo una manzana) y con la garantía de una demanda concentrada.

En todo caso no hay que confundir la manera en que la Participación en la Plusvalía pude controlar el mercado del suelo, con aquellas consecuencias que puede traer consigo la tardanza en la adopción de instrumentos de desarrollo (planes parciales, planes maestros, etc.) circunstancia que en últimas desestimula la inversión privada y desplaza estos recursos a otros renglones de la economía. En un foro recientemente llevado a cabo en la ciudad de Pereira se mencionaba cómo la zona norte de Bogotá donde los valores comerciales hasta hace pocos años eran verdaderamente especulativos no presentaba en estos momentos gran volumen de transacciones ni valores elevados en las pocas transacciones que se habían llevado a cabo, por lo cual concluía el expositor que se había controlado el valor del suelo; pero otra explicación a posible de este fenómeno es la falta de interés de los particulares por invertir en un zona con un cierto grado de incertidumbre jurídica, pues aparte de que han transcurrido seis años sin que se reglamente la zona, se sabe que hace más de ocho meses se encuentra terminado el Plan de Ordenamiento Zonal de este sector de la ciudad y aún no se ha sancionado el respectivo decreto de su adopción.

Es así como también la inseguridad jurídica de las actuaciones del Estado afecta el valor de los inmuebles (distinto a controlarlo) y como claro ejemplo podemos citar el predio de interés cultural conocido como Villa Adelaida, bastante deteriorado pero aún con elementos a conservar, ubicado en la Carrera $7^{\mathrm{a}}$ con Calle 70 de la ciudad de Bogotá, el cual ha sido objeto de una ardua polémica por la y competencia entre entidades del orden nacional y distrital en la que ha participado también la sociedad civil, respecto del potencial. El tema central de la polémica radica en los diferentes potenciales de uso y edificación que deberáestas entidades y la comunidad consideran deben permitirse, lo cual ha generado tal incertidumbre alrededor de su verdadero potencial, que este inmueble, por el cual fácilmente cualquier comprador interesado hubiera estado dispuesto a pagar una importante cifra por metro cuadrado, hoy ha vistove bastante reducida su posibilidad de comercialización a cualquier precio pues esson totalmente inciertainciertos su normatividad y el tiempo que puede transcurrir para superar este obstáculo.

\section{Consideraciones Finalesfinales}

La Ley 388 de 1997 define el marco normativo bajo el cual se debe establecer el cálculo del efecto plusvalía para cualquiera de los hechos generadores y de acuerdo a lo referenciado en el inciso 1 de los artículos 75, 76 y 77 de la mencionada Ley, "Se establecerá el precio comercial de los terrenos en cada una de las zonas o subzonas beneficiarias, con características geoeconómicas homogéneas, antes de la acción urbanística generadora de la 
plusvalía". En este sentido, es claro que los avalúos para el cálculo del efecto plusvalía, deben ser desarrollados bajo los procedimientos de zonas homogéneas geoeconómicas.

EL Decreto 1420 de 1998 y la Resolución 762 de 1998, establecen los métodos valuatorios aplicables en nuestro país para los fines del Estado contemplados en la citada ley. Específicamente la Resolución 762 determina como aplicables para los fines de la Ley los siguientes métodos: Método de Comparación o de Mercado, Método de Capitalización de Rentas o Ingresos, Método del Costo de Reposición y Método o Técnica Residual.

Desde el punto de vista de las técnicas y procedimientos que se han empleado para los cálculos del efecto plusvalía y su adecuada o no correspondencia con el espíritu normativo que busca la Ley 388 de 1997, se evidencian algunas situaciones que en concepto de los autores del presente artículo deberán ser analizadas y corregidas, para cuyo efecto se presentan algunas propuestas metodológicas de aplicación en el cálculo del efecto plusvalía.

- Las principales dificultades encontradas en la práctica de los avalúos para el cálculo del efecto plusvalía, radican en la falta de formación del profesional que enfrenta el cálculo. Nos referimos a deficiencias en su formación y/o desconocimiento de correcta aplicación de las técnicas valuatorias, esencialmente en el manejo de la técnica residual y de los métodos de comparación y renta, así como desconocimiento de los procesos que dicho análisis requiere de forma específica en cuanto a la definición de unas reglas claras y únicas de la forma y tipos de valoración.

- En relación a los métodos generales de valoración se debe empezar concretando que para los procesos de cálculo del efecto plusvalía se requiere básicamente la aplicación de dos métodos: el método de mercado o de comparación y la técnica residual. A la fecha y en una buena parte de los procesos de cálculo desarrollados, ha hecho carrera que el método de valoración para tal fin es únicamente la técnica residual, concepto que en opinión de los autores, no puede ser la única regla de valoración válida. Si bien es cierto que lo que se busca es establecer el incremento de valor que la propiedad percibe por efectos del cambio de uso y modificación de la edificabilidad del predio, y donde el método residual es una buena aproximación del valor, éste no puede convertirse en el único aplicable, por cuanto este tipo de técnicas es demasiado sensible a los cambios en los valores estimados, ya sea de venta, costos, utilidad y otros, lo que se traduce en oscilaciones significativas en el valor final de suelo. Se propone, que, además de la técnica residual, se debedeba sustentar los valores con datos de mercado que, como es obvio, deberán estar enfocados a la propiedad en estudio, tanto en sus condiciones físicas como normativas.

- Otra de las situaciones observadas que dificultan el desarrollola elaboración de los avalúos para el cálculo del efecto plusvalía, está asociado con la exigencia normativa del desarrollo de los valores del suelo por metodologías de zonas geoeconómicas homogéneas. Se ha evidenciado falta de este conocimiento específico en la generalidad de los avaluadores privados, debido a que históricamente el empleo de esta técnica siempre estuvo en manos de funcionarios del Instituto Geográfico Agustín Codazzi o de los Catastros descentralizados.

- La técnica residual debe desarrollarse bajo el principio de mayor y mejor uso, según el cual el valor de un inmueble susceptible de ser dedicado a diferentes usos será el que resulte de destinarlo, dentro de las posibilidades legales y físicas, al económicamente más rentable, o si es susceptible de ser construido con distintas intensidades edificatorias, será el que resulte de construirlo, dentro de las posibilidades legales y físicas, con la combinación de intensidades que permita obtener la mayor rentabilidad, 
principio que no está legalmente estipulado ${ }^{29}$ y que se desconoce por una parte significativa de los avaluadores.

- Además de la falta de una capacitación específica en cuanto a los métodos generales de valoración, la mayor dificultad observada para el cálculo del efecto plusvalía es la falta de conocimientos, formación y experiencia en la elaboración de zonas homogéneas físicas y geoeconómicas. Para estos procedimientos se ha desarrollado una serie de pasos o y criterios para su elaboración que han sido producto más de la experiencia de las instituciones competentes a cargo, que de una normatividad específica. No se puede desconocer que las zonas geoeconómicas son una alternativa más de aplicación en la valoración masiva.

- Se demanda por parte de los entes que solicitan el cálculo así como por los profesionales que los desarrollan, la formulación de una guía general donde se presenten de manera cronológica, de ser posible, las diferentes etapas y elementos mínimos con que se debe contar y que se deben producir, para el desarrollo de la implementación, cálculo y liquidación del efecto plusvalía.

- Observada la legislación pertinente, es oportuno anotar que si bien es cierto el Decreto 1788 de 2004 no estableció una fecha única para estimar los valores comerciales antes de la acción urbanística, no puede perderse de vista que el objeto del cálculo del efecto plusvalía es establecer el mayor valor que adquiere la tierra generado por una acción del Estado. En este sentido las técnicas o métodos valuatorios utilizados para el cálculo, deben propender por encontrar aquel incremento en valor ocasionado únicamente por la acción del Estado y lograr excluir aquellos incrementos en el valor de la tierra que son atribuibles a la dinámica inmobiliaria.

- Los autores sugieren que para lograr cumplir con el objetivo de valoración, se considere una análisis temporal diferente, en función de que los hechos generadores. Es decir, que para el cálculo del efecto plusvalía debido a la incorporación de suelo rural a suelo de expansión o la consideración de parte del suelo rural como suburbano, los valores comerciales iniciales se estableceránestablezcan un (1) año antes de la acción urbanística generadora de la plusvalía. De esta forma se evita que el cálculo del valor pueda llegar a verse afectado por las expectativas que genera el cambio de norma en los propietarios deseosos de concretarlas antes de la adopción de la nueva normatividad y que inciden directamente en los valores de pedido de los predios. Si la investigación se desarrolla con valores de un año antes de la acción generadora de plusvalía, se evitaría la incorporación de dichas expectativas no concretables aún. Para el cálculo del efecto plusvalía en los hechos generadores por mayor aprovechamiento y cambio de uso, en suelo urbano, los valores antes de la acción urbanística deben ser calculados justamente un día antes a la fecha de adopción del Plan de Ordenamiento Territorial, su revisión o de la adopción de los instrumentos que lo desarrollan y complementan. La anterior sugerencia para el cálculo de la plusvalía, se basa en que al hacerlo de esta forma se cuantifica exactamente el mayor beneficio generado 'exclusivamente' por el cambio de la norma urbanística, sin que se incluyan en este cálculo factores de tiempo, utilización de datos del pasado, empleo de índices de actualización que no son exclusivos del sector inmobiliario, o valorizaciones propias de la dinámica del mercado inmobiliario.

Para facilitar la comprensión de este fenómeno se muestra el siguiente ejemplo:

\footnotetext{
${ }^{29}$ Es decir, nuestra la reglamentación en términos vigente de avaluos, adolece dela Ley 388 sobre avalúos, no incluyó la definición específica del principio de mayor y mejor uso. La definición citada corresponde a los términos universalmente aceptados de este principio.
} 


\begin{tabular}{|l|r|r|}
\hline \multicolumn{2}{|c|}{ CALCULO EN UN SOLO MOMENTO. UN DIA ANTES } \\
\hline Area Lote & 600,00 & \\
\hline No. de Pisos & 5 & 8 \\
\hline Area Construida & $3.000,00$ & $4.800,00$ \\
\hline Area Vendible & $2.550,00$ & $4.080,00$ \\
\hline & & \\
\hline Valor en venta \$/M2 & 2.500 .000 & (a la fecha del cálculo) \\
\hline Valor construcción \$/M2 & 1.500 .000 & (a la fecha del cálculo) \\
\hline & & \\
\hline Total Ventas & 6.375 .000 .000 & 10.200 .000 .000 \\
\hline Total Construcción & -4.500 .000 .000 & -7.200 .000 .000 \\
\hline Finacieros (10\%) S.V. & -637.500 .000 & -1.020 .000 .000 \\
\hline Utilidad (15\%) S.V. & -956.250 .000 & -1.530 .000 .000 \\
\hline Residual Para el Terreno & 281.250 .000 & 450.000 .000 \\
\hline Valor \$/M2 de terreno & 468.750 & 750.000 \\
\hline \multicolumn{2}{|c|}{} & \\
\hline Plusvalia (100\%) & $\mathbf{2 8 1 . 2 5 0}$ & \\
\hline
\end{tabular}

Como se puede apreciar, si el cálculo se realiza en la forma propuesta, se estaría midiendo sin mayor complicación y con mejor precisión técnica el efecto real y directo de haber incrementado la potencialidad del lote y poder construir 8 y no 5 pisos.

Si por el contrario el cálculo se hiciese un año antes el desarrollo sería el siguiente:

\begin{tabular}{|c|c|c|}
\hline \multicolumn{3}{|c|}{ CALCULO UN AÑO ANTES } \\
\hline IPC (1 AÑO) & $5 \%$ & \\
\hline Area Lote & 600,00 & \\
\hline No. de Pisos & 5 & 8 \\
\hline Area Construida & $3.000,00$ & $4.800,00$ \\
\hline Area Vendible & $2.550,00$ & $4.080,00$ \\
\hline Valor en venta $\$ / \mathrm{M} 2$ & 2.250 .000 & (un año antes) \\
\hline Valor en venta $\$ / \mathrm{M} 2$ & 2.500 .000 & (a la fecha de calculo) \\
\hline Valor construcción \$/M2 & 1.350 .000 & (un año antes) \\
\hline Valor construcción \$/M2 & 1.500 .000 & (a la fecha del cálculo) \\
\hline Total Ventas & 5.737 .500 .000 & 9.180 .000 .000 \\
\hline Total Construcción & -4.050 .000 .000 & -6.480 .000 .000 \\
\hline Finacieros (10\%) S.V. & -573.750 .000 & -918.000 .000 \\
\hline Utilidad (15\%) S.V. & -860.625 .000 & -1.377 .000 .000 \\
\hline Residual Para el Terreno & 253.125 .000 & 405.000 .000 \\
\hline Valor \$/M2 de terreno & $\longrightarrow 421.875$ & 675.000 \\
\hline & (un año antes) & (a la fecha del cálculo) \\
\hline Valor $\$ / M 2$ de terreno Actualizado & 442.969 & 675.000 \\
\hline Plusvalia (100\%) & 232.031 & \\
\hline
\end{tabular}

Como se puede observar es necesario incluir dentro del cálculo del residual, datos tanto de construcción como de ventas de un año antes, situación que podría eventualmente dificultar la consecución de esta información. De otra parte, al final el valor del terreno debe ser actualizado con el Índice de Precios al Consumidor - IPC 
según lo disponen la Ley 388 de 1997 y el Decreto 1788 de 2004, pero en muchos casos la valorización ha superado de manera significativa este índice; por ejemplo mientras el IPC del 2005 fue de $4,85 \%{ }^{30}$ la valorización de la zona del Refugio en Bogotá fue del $18,75 \%$ y en Santa Bárbara Alta del $22,2 \%^{31}$.

Al utilizar esta técnica (1 año antes) la actualización del valor del terreno mediante el IPC puede dar un resultado como el del ejemplo anterior, es decir en donde el Estado "pierde" plusvalía; esto debido a que en una época de auge el IPC estará por debajo de la valorización y en una época de crisis el valor actualizado será superior al valor actual encontrado y no se capturaría plusvalía por un cambio normativo importante.

\section{BIBLIOGRAFIA}

Constitución Política de Colombia de 1991.

Decreto 855 de abril 28 de 1994 "Por el cual se reglamenta parcialmente la Ley 80 de 1993 en materia de contratación directa".

Decreto-Ley 2150 de diciembre 5 de 1995 "Por el cual se suprimen y reforman regulaciones, procedimientos o trámites innecesarios, existentes en la Administración Pública".

Ley 388 de julio 18 de 1997. Ley de Desarrollo Territorial "Por la cual se modifican la Ley 9a. de 1989 y la Ley $3^{a}$. de 1991 y se dictan otras disposiciones".

Decreto 1420 del 24 de julio de 1998 "Por el cual se reglamentan parcialmente el artículo 37 de la Ley $9^{a}$ de 1989, el artículo 27, el Decreto-ley 2150 de 1995, los artículos 56, 61, 62, 67, 75, 76, 77, 80, 82, 84 y 87 de la Ley 388 de 1997 y, el artículo 11 del Decreto-ley 151 de 1998, que hacen referencia al tema de avalúos".

Resolución 762 del 23 de Octubre de 1998 "Por la cual se establece la metodología para la realización de los avalúos ordenados por la Ley 388 de 1997".

Decreto Distrital 619 de julio 28 de 2000 "Por el cual se adopta el Plan de Ordenamiento Territorial para Santa Fe de Bogotá, Distrito Capital".

Decreto Distrital 469 de diciembre de 2003 "Por el cual se revisa el Plan de Ordenamiento Territorial de Bogotá, D.C".

Decreto Distrital 190 de junio de 2004 "Por medio del cual se compilan las disposiciones contenidas en los Decretos Distritales 619 de 2000 y 469 de 2003".

Decreto 1788 de junio 3 de 2004 "Por el cual se reglamentan parcialmente las disposiciones referentes a la participación en plusvalía de que trata la Ley 388 de 1997.

DEPARTAMENTO ADMINISTRATIVO DE CATASTRO DISTRITAL. Manual de elaboración de Zonas Homogéneas Físicas. 2004.

\footnotetext{
${ }^{30}$ Fuente: Dane.

${ }^{31}$ Datos referidos a la ciudad de Bogotá tomados del estudio "El Valor del Suelo en Bogotá - 2005". Lonja de Propiedad Raiz de Bogotá.
} 
DEPARTAMENTO ADMINISTRATIVO DE CATASTRO DISTRITAL. Manual de elaboración de Zonas Geoeconómicas. 2004.

Foro: Región, Gestión del suelo y Participación en Plusvalías. Universidad de los Andes. Bogotá D.C. Mayo 27 y 28 de 2004. Conferencia: Alcaldía Mayor de Bogota D.C. Proyecto de Acuerdo "Por el cual se establecen las normas para la aplicación de la Participación en Plusvalías en Bogota D.C".

Foro: Región, Gestión del suelo y Participación en Plusvalías. Universidad de los Andes. Bogotá D.C. Mayo 27 y 28 de 2004. Conferencia: Maldonado María Mercedes. Notas de Clase, Instrumentos de Gestión del Suelo - Algunos Elementos de Contexto.

Foro: Región, Gestión del suelo y Participación en Plusvalías. Universidad de los Andes. Bogotá D.C. Mayo 27 y 28 de 2004. Conferencia: Maldonado María Mercedes. El Proceso de Construcción del Sistema Urbanístico Colombiano: Entre Ordenamiento Territorial y Reforma Urbana.

Foro: Región, Gestión del suelo y Participación en Plusvalías. Universidad de los Andes. Bogotá D.C. Mayo 27 y 28 de 2004. Conferencia: Jaramillo Samuel. La Experiencia Colombiana en la Recuperación Estatal de los Incrementos del Precio del Suelo. La Contribución de Valorización y La Participación en Plusvalías.

Jaramillo González, Samuel. Notas Sobre el Mecanismo de Participación en Plusvalía. Reforma Urbana y Desarrollo Territorial. Bogota D.C. 2003.

Delgado, Jorge, Moreno, Oliverio y Vivas Adriana. "Metodología para el Cálculo del Efecto Plusvalía Resultado del Mayor Aprovechamiento del Suelo". Tesis de Grado, Especialización en Avalúos, Universidad Distrital Francisco José de Caldas, Bogotá, 20 